\title{
Article
}

\section{Time-Varying Insomnia Symptoms and Incidence of Cognitive Impairment and Dementia among Older US Adults}

\author{
Nicholas V. Resciniti ${ }^{1, *}$, Valerie Yelverton ${ }^{2}{ }^{\circledR}$, Bezawit E. Kase ${ }^{1}$, Jiajia Zhang ${ }^{1}$ and Matthew C. Lohman ${ }^{1}(0)$ \\ 1 Department of Epidemiology and Biostatistics, Arnold School of Public Health, University of South Carolina, \\ Columbia, SC 29201, USA; bkase@email.sc.edu (B.E.K.); JZHANG@mailbox.sc.edu (J.Z.); \\ LOHMANM@mailbox.sc.edu (M.C.L.) \\ 2 Department of Health Services Policy \& Management, Arnold School of Public Health, \\ University of South Carolina, Columbia, SC 292901, USA; VYELVERT@mailbox.sc.edu \\ * Correspondence: rescinin@email.sc.edu
}

check for

updates

Citation: Resciniti, N.V.; Yelverton, V.; Kase, B.E.; Zhang, J.; Lohman, M.C. Time-Varying Insomnia Symptoms and Incidence of Cognitive Impairment and Dementia among Older US Adults. Int. J. Environ. Res. Public Health 2021, 18, 351. https://doi.org/ 10.3390/ijerph18010351

Received: 9 December 2020 Accepted: 31 December 2020 Published: 5 January 2021

Publisher's Note: MDPI stays neutral with regard to jurisdictional clai$\mathrm{ms}$ in published maps and institutional affiliations.

Copyright: (C) 2021 by the authors. Licensee MDPI, Basel, Switzerland. This article is an open access article distributed under the terms and conditions of the Creative Commons Attribution (CC BY) license (https:// creativecommons.org/licenses/by/ $4.0 /)$.

\begin{abstract}
There is conflicting evidence regarding the association between insomnia and the onset of mild cognitive impairment (MCI) or dementia. This study aimed to evaluate if time-varying insomnia is associated with the development of MCI and dementia. Data from the Health and Retirement Study ( $n=13,833$ ) from 2002 to 2014 were used (59.4\% female). The Brief Insomnia Questionnaire was used to identify insomnia symptoms which were compiled in an insomnia severity index, ranging from 0 to 4 . In analysis, participants' symptoms could vary from wave-to-wave. Dementia was defined using results from the Health and Retirement Study (HRS) global cognitive assessment tool. Respondents were classified as either having dementia, MCI, or being cognitively healthy. Cox proportional hazards models with time-dependent exposure using the counting process (start-stop time) were used for analysis. For each one-unit increase in the insomnia symptom index, there was a 5-percent greater hazard of $\mathrm{MCI}(\mathrm{HR}=1.05 ; 95 \% \mathrm{CI}: 1.04-1.06)$ and dementia $(\mathrm{HR}=1.05$; 95\% CI: 1.03-1.05), after fully adjusting. Using a nationally representative sample of adults age 51 and older, this study found that time-varying insomnia symptoms are associated with risk of MCI and dementia. This highlights the importance of identifying sleep disturbances and their change over time as potentially important risk factors for $\mathrm{MCI}$ and dementia.
\end{abstract}

Keywords: dementia; cognitive impairment; time-varying; insomnia; older adults; sleep

\section{Introduction}

Dementia is a progressive neurodegenerative disorder affecting individuals' brain function, memory, and activities of daily living [1]. The prevalence of dementia is expected to triple in the next 40 years, leading to an estimated 14 million people with dementia by 2060 [2]. The Alzheimer's Association estimates the total direct medical expenditures related to Alzheimer's disease-related dementias (ADRD) will increase from $\$ 236$ billion in 2016 to over \$1 trillion in 2050 [3].

Mild cognitive impairment (MCI) is defined as self- or informant-reported functional impairment or impaired test performance on neuropsychological measures that does not reach the severity of dementia [4]. MCI can be a precursor of dementia [5,6], with over 30 percent of individuals diagnosed with MCI progressing to dementia within five years [1]. MCI is estimated to affect 15-20 percent of older adults in the US [1,7-9]. While there are several subtypes of MCI with diverse etiology, there is still much debate regarding the pathogenesis of MCI and dementia [5]. Previous research has identified several modifiable and immutable factors contributing to an individual's risk for dementia and MCI including socio-demographics, comorbidities, family history, and lifestyle factors [1,5,8,10-12].

Growing evidence has linked sleep disturbances and insomnia to greater risk of MCI and dementia [13-24]. In particular, the association between insomnia, which includes difficulty falling asleep, awakening during the night, early-awakening without being able 
to fall asleep again, and non-restorative sleep [25], and cognitive decline has received significant research attention. Results from several studies indicate that individuals with insomnia are more likely to have clinically significant alterations in attention and episodic memory and more likely to develop dementia [26-28]. However, very little is known regarding the frequency or level of insomnia that would result in $\mathrm{MCI}$ and dementia. Published studies examining the associations between insomnia and $\mathrm{MCI}$ or dementia have predominantly assumed insomnia symptoms to be stagnant over time or have not considered the severity or type of insomnia symptoms [14,17,29-32]. These assumptions may be especially tenuous among older adult populations, as previous research shows that insomnia symptoms vary significantly over time and frequently increase as individuals get older [28]. Further, research suggests that measuring insomnia at only one timepoint may lead to biased estimates of the associations with MCI and dementia, which may have important implications for public health and clinical approaches to addressing cognitive health [31]. Thus, to understand the role of insomnia in the development of MCI and dementia, it is necessary to distinguish chronic insomnia disorder from presence of insomnia symptoms at a single point in time.

Given the limitations of previous analyses, this study examined the dynamic effect of changes in insomnia on cognitive decline and dementia over time. Our primary aim was to estimate the association between time-varying insomnia and $\mathrm{MCI}$ or dementia using a nationally representative cohort of US adults age 51 and older from 2002 to 2014 . We hypothesized that time-varying insomnia symptoms would be associated with greater risk of incident MCI and dementia.

\section{Materials and Methods}

\subsection{Database}

This study used data from the Health and Retirement Study (HRS), a biennial, population-based survey of older adults in the United States conducted by the University of Michigan and sponsored by the National Institute on Aging (NIA U01AG009740). HRS sample collection is based on a multi-stage probability design meant to produce a nationally representative sample of adults over the age of 50 [33]. Thirty-five sample weights are provided to account for the complex sampling design and to make inferences regarding the general US population. Respondents are re-interviewed every two years and asked questions related to health status, healthcare utilization, cognition, and demographics [33]. The present study used data from seven HRS waves (2002 to 2014). Of individuals who completed the HRS core survey during the study period, 18,166 adults age 51 and older provided data on their cognitive status and insomnia symptoms at baseline. We excluded respondents who were found to have MCI $(n=2996)$ or dementia $(n=1337)$ at baseline leading to the final analytic sample of 13,833 participants who were cognitively healthy at baseline.

\subsection{Outcome Variables}

$\mathrm{MCI}$ and dementia were assessed at each wave of HRS using a global test of several cognitive domains, such as working memory, word recall, language, and orientation; the internal consistency reliability coefficient was about 0.65 [34]. Scores were summed to a composite score that ranged from 0 to 35 [34]. To determine MCI and dementia, we used a previously validated classification approach developed using HRS data [35]. The orientation and language domains were first excluded from the full HRS cognitive score, yielding a composite score ranging from 0 to 27 [35]. Respondents who scored 0 to 6 were classified as having dementia, those who scored from 7 to 11 were classified as being cognitively impaired with no dementia (MCI), and respondents scoring from 12 to 27 were considered not cognitively impaired. 


\subsection{Exposure Variable}

Insomnia symptoms were assessed using the Adapted Brief Insomnia Questionnaire (BIQ) [36]. Trouble falling asleep, waking up during the night, waking up too early and not being able to fall asleep again most of the time and feeling really rested when you wake up in the morning rarely or never were considered to be insomnia symptoms. Insomnia was assessed as a severity score from 0 (no symptoms) to 4 (the most symptoms) [36,37].

\subsection{Covariate Variables}

Demographic characteristics considered for model adjustment were baseline (wave 2002) age, gender, race, and education. A baseline chronic disease index was calculated by summing indicators of high blood pressure, diabetes, cancer, lung disease, heart disease, stroke, psychiatric problems, and arthritis. Additional baseline health information used in adjustment were body mass index (BMI), smoking status, and number of alcoholic drinks consumed when drinking. Model covariates were selected based on literature review and an empirical confounder assessment. If adjustment for a potential confounder produced at least a $10 \%$ change in estimate compared to the crude association, it was kept in the final model.

\subsection{Data Analysis}

Descriptive statistics of the baseline sample were calculated with percent and means for categorical and continuous variables, respectively. Frequencies of self-reported insomnia symptoms and the change from wave-to-wave were calculated and depicted visually using a Sankey diagram. Adjusted and unadjusted Cox proportional hazards models with time-dependent exposure were used to estimate the associations between insomnia and subsequent incidence of MCI or dementia. Specifically, the counting process model, an extension of the Cox model, was applied to account for the longitudinal information on insomnia, where the follow-up period was divided into intervals (start and stop time) based on each wave [38]. Lastly, each model was stratified by baseline age categories (51-64 and 65 and older; effect modification results were not presented since effect modification by age was not significant) to understand if there was effect modification at baseline by age. HRS analytic weights and stratification variables were applied to all hazard models to account for the complex sample design. All analyses were completed with SAS (Statistical Analysis System) version 9.4 (SAS institute, Cary, NC, USA).

\section{Results}

\subsection{Study Sample Characteristics}

The analytic sample included 13,833 participants without MCI or dementia at baseline. The mean age of participants was 66.41 years ( $\mathrm{SD}=9.52$ years), and $59 \%$ were females. A majority of participants were white $(86 \%)$ and $17 \%$ had less than high school education. The baseline mean insomnia severity score was 0.58 with a SD of 0.92 (see Table 1 ). The Sankey diagram (Figure 1) shows that the percentages of each insomnia symptom category at each wave were consistent in the period 2002-2006, 2010, and 2014; however, there was substantial fluctuation of reported insomnia symptoms by individuals from wave-towave. The fluctuation of symptoms suggests that self-reported insomnia symptoms are time-varying. 


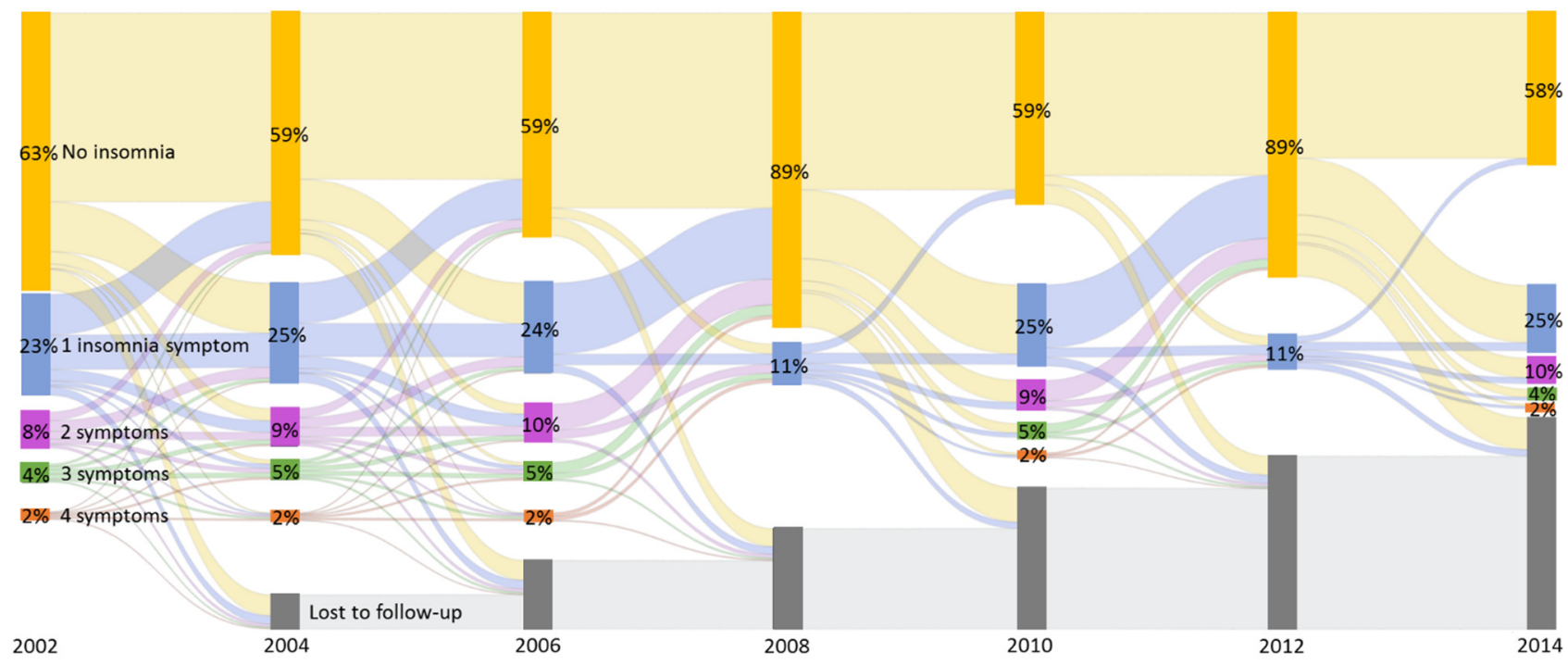

Figure 1. Fluctuation of self-reported insomnia symptoms over time (2002-2014). Different colors indicate the classification of information (yellow: no or 0 self-reported insomnia symptoms; blue = 1 self-reported insomnia symptom; purple = 2 selfreported insomnia symptoms; green $=3$ self-reported insomnia symptoms; orange $=4$ self-reported insomnia symptoms) . Classification of insomnia symptoms is limited to 0 or 1 insomnia symptom(s) in 2008 and 2012. Changes of self-reported insomnia symptoms are represented by curved lines. Data source: Health and Retirement Study (2002-2014).

Table 1. Baseline sample characteristics.

\begin{tabular}{cc}
\hline Baseline Characteristics & $\begin{array}{c}\text { Total Sample } \\
\mathbf{N}=\mathbf{1 3}, \mathbf{8 3 3}\end{array}$ \\
\hline Baseline insomnia (SD) & $0.58(0.92)$ \\
Age mean (SD) & $66.41(9.52)$ \\
Gender (\% Female) & $59.37 \%$ \\
Race (\% White) & $86.29 \%$ \\
Education (\% Less than high school) & $17.25 \%$ \\
BMI mean (SD) & $27.38(5.30)$ \\
Drinks per day (SD) & $0.63(0.01)$ \\
Smoking status (\%Smoker) & 14.13 \\
Chronic disease Index (\% No Chronic illness) & 19.45 \\
\hline
\end{tabular}

Note: Chronic disease index includes high blood pressure, diabetes, cancer, lung disease, heart disease, stroke, psychiatric problems, and arthritis.

\subsection{Cox Proportional Hazards Model with Time-Varying Insomnia}

Table 2 shows the unadjusted and adjusted hazard ratios between time-varying insomnia on $\mathrm{MCI}$ and dementia. Time-varying insomnia was significantly associated with both $\mathrm{MCI}$ and dementia in both adjusted and unadjusted models. Each one-unit increase in the insomnia symptom index was associated with a 5 percent greater hazard of $\mathrm{MCI}(\mathrm{HR}=1.05$; 95\% CI: 1.04-1.06), after controlling for baseline age, race, gender, education, BMI, smoking status, drinking, and the chronic disease index. Each one-unit increase in the insomnia symptom index was associated with a 5 percent greater hazard of dementia $(\mathrm{HR}=1.05$; 95\% CI: 1.03-1.05), after controlling for baseline race, gender, education, BMI, smoking status, drinking, and the chronic disease index. Further stratified analyses according to baseline age were performed but did not find significant differences in the associations between insomnia and $\mathrm{MCI}$ or dementia by age (results not presented). 
Table 2. Unadjusted and adjusted hazard ratios between time-varying insomnia, mild cognitive impairment, and dementia.

\begin{tabular}{|c|c|c|c|c|c|}
\hline & & \multicolumn{2}{|c|}{ Mild Cognitive Impairment } & \multicolumn{2}{|c|}{ Dementia } \\
\hline & & Unadjusted & Adjusted * & Unadjusted & Adjusted * \\
\hline Insomnia & & $1.10^{\wedge}(1.09-1.11)$ & $1.05^{\wedge}(1.04-1.06)$ & $1.09^{\wedge}(1.07-1.10)$ & $1.05^{\wedge}(1.03-1.06)$ \\
\hline Age (Years) & & & $1.06^{\wedge}(1.06-1.06)$ & & $1.11^{\wedge}(1.11-1.11)$ \\
\hline \multicolumn{6}{|l|}{ Education } \\
\hline & Less than High School & & $3.60^{\wedge}(3.59-3.60)$ & & $2.67^{\wedge}(2.66-2.68)$ \\
\hline & GED & & $2.42^{\wedge}(2.42-2.43)$ & & $1.84^{\wedge}(1.83-1.84)$ \\
\hline & High School Graduate & & $2.03^{\wedge}(2.02-2.03)$ & & $1.48^{\wedge}(1.47-1.48)$ \\
\hline & Some College & & $1.53^{\wedge}(1.53-1.53)$ & & $1.19^{\wedge}(1.19-1.20)$ \\
\hline \multirow{4}{*}{ Race } & College and Above & & Ref & & Ref \\
\hline & White & & Ref & & Ref \\
\hline & Black & & $1.95^{\wedge}(1.95-1.95)$ & & $2.09^{\wedge}(2.08-2.10)$ \\
\hline & Other & & $1.62^{\wedge}(1.61-1.62)$ & & $1.61^{\wedge}(1.60-1.62)$ \\
\hline \multirow[t]{2}{*}{ Gender } & Male & & Ref & & Ref \\
\hline & Female & & $0.81^{\wedge}(0.81-0.81)$ & & $0.98^{\wedge}(0.98-0.98)$ \\
\hline \multirow{2}{*}{ Smoking } & No & & Ref & & Ref \\
\hline & Yes & & $1.25^{\wedge}(1.24-1.25)$ & & $1.36^{\wedge}(1.36-1.37)$ \\
\hline BMI & & & $1.00(0.99-1.00)$ & & $0.98^{\wedge}(0.98-0.98)$ \\
\hline $\begin{array}{c}\text { Number of } \\
\text { Chronic Diseases }\end{array}$ & & & $1.08^{\wedge}(1.08-1.08)$ & & $1.59^{\wedge}(1.59-1.59)$ \\
\hline Number of Drinks & & & $0.96^{\wedge}(0.96-0.96)$ & & $0.91^{\wedge}(0.91-0.92)$ \\
\hline
\end{tabular}

Note: * adjusted for baseline age, gender, race, education, body mass index, drinking, smoking status, and chronic disease index; ${ }^{p} p$-value $<0.05$.

\section{Discussion}

Using a nationally representative sample of adults age 51 and older, this study found that time-varying insomnia severity was associated with a greater likelihood of developing $\mathrm{MCI}$ and dementia over time. In support of our hypothesis, over 12 years of followup, results suggested that for each additional insomnia symptom, there was a 5 percent greater hazard of incident $\mathrm{MCI}(\mathrm{HR}=1.05 ; 95 \% \mathrm{CI}: 1.04-1.06)$ and dementia (HR = 1.05; 95\% CI: 1.03-1.06), after adjusting for baseline gender, race, education, BMI, smoking status, drinking status, and chronic disease index.

Previous research regarding the associations between insomnia and $\mathrm{MCI} /$ dementia are mixed and sometimes contradictory. For instance, Hung et al. (2018) found that insomnia was associated with a 2.14 times greater dementia risk [28]. Conversely, Lysen et al. (2018) found that sleep quality was not associated with incident dementia (HR: 0.91; 95\% CI: 0.82-1.02) [39]; however, these studies used different sleep measures and different study designs and did not account for time-varying insomnia symptoms, which may explain inconsistent results. Our findings are consistent with a positive association between insomnia and greater risk of incident cognitive decline and dementia. The degree of risk is similar to that found in a meta-analysis by Xu et al. (2020) [23].

Differences between our study and previously conducted studies with different or null findings could be related to several methodologic and sample differences. Our study used a longitudinal study design with time-varying insomnia, while other studies have used cross-sectional [23] or case-control [28] study design or assessed insomnia only at baseline [39]. Additionally, we considered insomnia symptoms on a continuous scale while other studies used clinical diagnosis [28] or categorical insomnia definitions [23]. Consistent with previous research, our results demonstrate that insomnia symptoms vary significantly over time [40,41]. The use of time-invariant insomnia symptoms in analysis may thus fail to distinguish the effects of chronic insomnia from more transient insomnia episodes, for instance due to illness or use of medications. Previous research shows that a significant proportion of people with transient insomnia might not develop chronic insomnia and the consequences of transient insomnia may be subtle [42]. In contrast, chronic insomnia has been associated with a wide range of deleterious health consequences 
including an increased risk of hypertension, diabetes, obesity, depression, heart attack, and stroke, $[28,43]$, which are also related to risk of cognitive decline and dementia. Information about the duration and changing severity of insomnia may thus provide more information about the cumulative effects of insomnia, both directly and indirectly, on cognition.

Several potential mechanisms have been proposed to explain how insomnia may increase risk of MCI and dementia. First, poor sleep—as defined by insomnia, sleep duration, sleep quality, intake of hypnotics, and sleep-disorder related to breathing - has been shown to be associated with neuronal degradation, structural changes of the brain and lower brain volumes $[44,45]$. A recent review by Joo (2015) found that insomnia may be associated with abnormal brain structures in the frontal cortex, hippocampus, and anterior cingulate cortex, areas important for memory, executive functions and other cognitive domains. These changes were due to a decrease in gray matter volumes in key regions associated with cognitive function [44]. More specifically, the researchers found evidence of greater atrophy among those with insomnia compared to controls in the CA2-4-DG region of the hippocampus, which was associated with impairment in verbal information processing, verbal memory, verbal processing, and visual memory [45]. Additional studies have found that insomnia symptoms in aging populations are independently associated with neuronal loss in the hippocampus [46]. During healthy sleep, the human brain clears amyloid-beta $(\mathrm{A} \beta)$ peptide accumulated during wake phases via the glymphatic pathway $[47,48]$. Sleep disturbances may thus interrupt or hamper this process resulting in an accumulation of $\mathrm{A} \beta$ in the brain, a hallmark of AD pathogenesis [49]. Alternatively, some research suggests that there may be a bidirectional association between sleep disturbances, MCI and dementia [49-51]. This bidirectional association may suggest that preclinical MCI or dementia may be influencing the development of insomnia followed by the development of detectable cognitive problems. Further, several modifiable and immutable factors, such as socio-demographics, comorbidities, family history, and lifestyle factors, are associated with insomnia, and over time, can lead to cognitive problems, including dementia and MCI [1,5,8,10-12].

The current study has many strengths, including a large sample size, 12-year followup, and use of a representative sample of adults age 51 and over in the United States; however, there are some limitations to note. First, insomnia symptoms were self-reported from the BIQ questionnaire and were compiled into an unweighted linear symptom index assuming equal weighting of all symptoms. Additionally, we were unable to confirm a clinical diagnosis of insomnia. Second, both outcome variables relied on cognitive and neuropsychological tests. Using imaging methods and/or clinical diagnosis of MCI and dementia could have led to different estimates of the association with insomnia. Last, this study did not differentiate between types of dementias which and cannot be interpreted in the light of specific forms of dementia, just an overall assessment. Future research should focus on understanding how time-varying insomnia is differentially associated with MCI and dementia compared to baseline or time-invariant insomnia. Additionally, it should be understood whether time-variant insomnia is associated with structural brain changes similar to those found in previous research.

\section{Conclusions}

In conclusion, this study showed that participants with more insomnia symptoms had an increased risk of MCI and dementia. The current results, in conjunction with other studies, highlight the importance of identifying sleep disturbances as a potentially important risk factor for the development of MCI and dementia. It is especially important for primary care providers to assess their patients' risk of sleep problems, as they may be able to intervene to prevent or delay the onset of $\mathrm{MCI}$ or dementia through lifestyle changes (e.g., more exercise or less coffee and alcohol) and behavioral therapy. Future studies should identify the association between fluctuating insomnia symptoms and specific forms of dementia. 
Author Contributions: Conceptualization, N.V.R., B.E.K. and V.Y.; methodology, N.V.R., B.E.K., M.C.L., J.Z. and V.Y.; software, N.V.R., B.E.K., J.Z. and V.Y.; validation, N.V.R., B.E.K. and V.Y.; formal analysis, N.V.R., B.E.K., J.Z. and V.Y.; investigation, N.V.R., B.E.K., M.C.L., J.Z. and V.Y.; writingoriginal draft preparation, N.V.R., B.E.K., M.C.L. and V.Y.; writing-review and editing, N.V.R., B.E.K., M.C.L., J.Z. and V.Y.; visualization, N.V.R. and V.Y.; supervision, M.C.L. and J.Z.; All authors have read and agreed to the published version of the manuscript.

Funding: This research received no external funding.

Informed Consent Statement: Not applicable.

Data Availability Statement: Publicly available datasets were analyzed in this study. This data can be found here: https://hrs.isr.umich.edu/data-products.

Conflicts of Interest: The authors declare no conflict of interest.

\section{References}

1. Alzheimer's Association. 2018 Alzheimer's Disease Facts and Figures. Alzheimer's Dement. 2018, 14, 367-429. [CrossRef]

2. Matthews, K.A.; Xu, W.; Gaglioti, A.H.; Holt, J.B.; Croft, J.B.; Mack, D.; McGuire, L.C. Racial and ethnic estimates of Alzheimer's disease and related dementias in the United States (2015-2060) in adults aged >/=65 years. Alzheimers Dement. 2019, 15, 17-24. [CrossRef]

3. Alzheimer's Association. Alzheimer's Disease Facts and Figures. Alzheimer's Dement. 2016, 12, 459-509.

4. Plassman, B.L.; Langa, K.M.; Fisher, G.G.; Heeringa, S.G.; Weir, D.R.; Ofstedal, M.B.; Burke, J.R.; Hurd, M.D.; Potter, G.G.; Rodgers, W.L.; et al. Prevalence of cognitive impairment without dementia in the United States. Ann. Intern. Med. 2008, $148,427$. [CrossRef] [PubMed]

5. Petersen, R.C.; Caracciolo, B.; Brayne, C.; Gauthier, S.; Jelic, V.; Fratiglioni, L. Mild cognitive impairment: A concept in evolution. J. Intern. Med. 2014, 275, 214-228. [CrossRef] [PubMed]

6. Albert, M.S.; DeKosky, S.T.; Dickson, D.; Dubois, B.; Feldman, H.H.; Fox, N.C.; Gamst, A.; Holtzman, D.M.; Jagust, W.J.; Petersen, R.C.; et al. The diagnosis of mild cognitive impairment due to Alzheimer's disease: Recommendations from the National Institute on Aging-Alzheimer's Association workgroups on diagnostic guidelines for Alzheimer's disease. Alzheimers Dement. 2011, 7, 270-279. [CrossRef] [PubMed]

7. Ganguli, M.; Chang, C.C.H.; Snitz, B.E.; Saxton, J.A.; Vanderbilt, J.; Lee, C.W. Prevalence of mild cognitive impairment by multiple classifications: The Monongahela-Youghiogheny Healthy Aging Team (MYHAT) project. Am. J. Geriatr. Psychiatry 2010, 18, 674-683. [CrossRef]

8. $\quad$ Petersen, R.C.; Roberts, R.O.; Knopman, D.S.; Geda, Y.E.; Cha, R.H.; Pankratz, V.S.; Boeve, B.F.; Tangalos, E.G.; Ivnik, R.J.; Rocca, W.A. Prevalence of mild cognitive impairment is higher in men. Mayo Clin. Study Aging Neurol. 2010, 75, 889-897.

9. Roberts, R.; Knopman, D.S. Classification and epidemiology of MCI. Clin. Geriatr. Med. 2013, 29, 753-772. [CrossRef] [PubMed]

10. Ju, Y.E.S.; McLeland, J.S.; Toedebusch, C.D.; Xiong, C.; Fagan, A.M.; Duntley, S.P.; Morris, J.C.; Holtzman, D.M. Sleep quality and preclinical Alzheimer disease. JAMA Neurol. 2013, 70, 587-593. [CrossRef]

11. Larsson, C.S.; Wolk, A. The Role of Lifestyle Factors and Sleep Duration for Late-Onset Dementia: A Cohort Study. J. Alzheimers Dis. 2018, 66, 579-586. [CrossRef] [PubMed]

12. Livingston, G.; Sommerlad, A.; Orgeta, V.; Costafreda, S.G.; Huntley, J.; Ames, D.; Ballard, C.; Banerjee, S.; Burns, A.; CohenMansfield, J.; et al. Dementia prevention, intervention, and care. Lancet 2017, 390, 2673-2734. [CrossRef]

13. Burke, S.L.; Cadet, T.; Alcide, A.; O'Driscoll, J.; Maramaldi, P. Psychosocial risk factors and Alzheimer's disease: The associative effect of depression, sleep disturbance, and anxiety. Aging Ment. Health 2018, 22, 1577-1584. [CrossRef] [PubMed]

14. Lim, A.S.; Kowgier, M.; Yu, L.; Buchman, A.S.; Bennett, D.A. Sleep Fragmentation and the Risk of Incident Alzheimer's Disease and Cognitive Decline in Older Persons. Sleep 2013, 36, 1027-1032. [CrossRef]

15. Lutsey, P.L.; Misialek, J.R.; Mosley, T.H.; Gottesman, R.F.; Punjabi, N.M.; Shahar, E.; MacLehose, R.; Ogilvie, R.P.; Knopman, D.; Alonso, A. Sleep characteristics and risk of dementia and Alzheimer's disease: The Atherosclerosis Risk in Communities Study. Alzheimers Dement. 2018, 14, 157-166. [CrossRef] [PubMed]

16. Shi, L.; Chen, S.J.; Ma, M.Y.; Bao, Y.P.; Han, Y.; Wang, Y.M.; Shi, J.; Vitiello, M.V.; Lu, L. Sleep disturbances increase the risk of dementia: A systematic review and meta-analysis. Sleep Med. Rev. 2018, 40, 4-16. [CrossRef]

17. Indi, S.; Kåreholt, I.; Johansson, L.; Skoog, J.; Sjöberg, L.; Wang, H.X.; Johansson, B.; Fratiglioni, L.; Soininen, H.; Solomon, A.; et al. Sleep disturbances and dementia risk: A multicenter study. Alzheimers Dement. 2018, 14, 1235-1242.

18. Virta, J.J.; Heikkilä, K.; Perola, M.; Koskenvuo, M.; Räihä, I.; Rinne, J.O.; Kaprio, J. Midlife sleep characteristics associated with late life cognitive function. Sleep 2013, 36, 1533-1541. [CrossRef]

19. Bubu, O.M.; Brannick, M.; Mortimer, J.; Umasabor-Bubu, O.; Sebastião, Y.V.; Wen, Y.; Schwartz, S.; Borenstein, A.R.; Wu, Y.; Morgan, D.; et al. Sleep, Cognitive impairment, and Alzheimer's disease: A Systematic Review and Meta-Analysis. Sleep 2017, 40. [CrossRef]

20. Osorio, R.S.; Pirraglia, E.; Agüera-Ortiz, L.F.; During, E.H.; Sacks, H.; Ayappa, I.; Walsleben, J.; Mooney, A.; Hussain, A.; Glodzik, L.; et al. Greater risk of Alzheimer's disease in older adults with insomnia. J. Am. Geriatr. Soc. 2011, 59, 559-562. [CrossRef] 
21. Leng, Y.; McEvoy, C.T.; Allen, I.E.; Yaffe, K. Association of Sleep-Disordered Breathing with Cognitive Function and Risk of Cognitive Impairment: A Systematic Review and Meta-analysis. JAMA Neurol. 2017, 74, 1237-1245. [CrossRef]

22. de Almondes, K.M.; Costa, M.V.; Malloy-Diniz, L.F.; Diniz, B.S. Insomnia and risk of dementia in older adults: Systematic review and meta-analysis. J. Psychiatr. Res. 2016, 77, 109-115. [CrossRef] [PubMed]

23. Xu, W.; Tan, C.C.; Zou, J.J.; Cao, X.P.; Tan, L. Sleep problems and risk of all-cause cognitive decline or dementia: An updated systematic review and meta-analysis. J. Neurol. Neurosurg. Psychiatry 2019, 91, 236-244. [CrossRef] [PubMed]

24. Wardle-Pinkston, S.; Slavish, D.C.; Taylor, D.J. Insomnia and cognitive performance: A systematic review and meta-analysis. Sleep Med. Rev. 2019, 48, 101205. [CrossRef] [PubMed]

25. Ateia, J.M.; Nowell, P.D. Insomnia. Lancet 2004, 364, 1959-1973.

26. Cross, N.E.; Carrier, J.; Postuma, R.B.; Gosselin, N.; Kakinami, L.; Thompson, C.; Chouchou, F.; Dang-Vu, T.T. Association between insomnia disorder and cognitive function in middle-aged and older adults: A cross-sectional analysis of the Canadian Longitudinal Study on Aging. Sleep 2019, 42, zsz114. [CrossRef]

27. Fortier-Brochu, É.; Morin, C.M. Cognitive Impairment in Individuals with Insomnia: Clinical Significance and Correlates. Sleep 2014, 37, 1787-1798. [CrossRef]

28. Hung, C.-M.; Li, Y.C.; Chen, H.J.; Lu, K.; Liang, C.L.; Liliang, P.C.; Tsai, Y.D.; Wang, K.W. Risk of dementia in patients with primary insomnia: A nationwide population-based case-control study. BMC Psychiatry 2018, 18, 38. [CrossRef]

29. Yaffe, K.; Nettiksimmons, J.; Yesavage, J.; Byers, A. Sleep Quality and Risk of Dementia Among Older Male Veterans. Am. J. Geriatr. Psychiatry 2015, 23, 651-654. [CrossRef]

30. Sindi, S.; Johansson, L.; Skoog, J.; Mattsson, A.D.; Sjöberg, L.; Wang, H.X.; Fratiglioni, L.; Kulmala, J.; Soininen, H.; Solomon, A.; et al. Sleep disturbances and later cognitive status: A multi-centre study. Sleep Med. 2018, 52, 26-33. [CrossRef]

31. Foley, D.; Monjan, A.; Masaki, K.; Ross, W.; Havlik, R.; White, L.; Launer, L. Daytime sleepiness is associated with 3-year incident dementia and cognitive decline in older Japanese-American men. J. Am. Geriatr. Soc. 2001, 49, 1628-1632. [CrossRef] [PubMed]

32. Burke, S.L.; Hu, T.; Spadola, C.E.; Li, T.; Naseh, M.; Burgess, A.; Cadet, T. Mild cognitive impairment: Associations with sleep disturbance, apolipoprotein e4, and sleep medications. Sleep Med. Res. 2018, 52, 168-176. [CrossRef] [PubMed]

33. Health and Retirement Study (HRS). The Health and Retirement Study. 2019. Available online: https://hrs.isr.umich.edu/about (accessed on 22 November 2019).

34. Ofstedal, M.B.; Fisher, G.G.; Herzog, A.R.; Wallace, R.B.; Weir, D.R.; Langa, K.M. HRS/AHEAD Documentation Report. Documentation of Cognitive Functioning Measures in the Health and Retirement Study. 2005. Available online: https://hrs.isr. umich.edu/sites/default/ files/biblio/dr-006.pdf (accessed on 14 February 2020).

35. Crimmins, E.M.; Kim, J.K.; Langa, K.M.; Weir, D.R. Assessment of cognition using surveys and neuropsychological assessment: The Health and Retirement Study and the Aging, Demographics, and Memory Study. J. Gerontol. B Psychol. Sci. Soc. Sci. 2011, 66 (Suppl. 1), i162-i171. [CrossRef] [PubMed]

36. Leggett, A.N.; Sonnega, A.J.; Lohman, M.C. The association of insomnia and depressive symptoms with all-cause mortality among middle-aged and old adults. Int. J. Geriatr. Psychiatry 2018. [CrossRef] [PubMed]

37. Jaussent, I.; Bouyer, J.; Ancelin, M.L.; Berr, C.; Foubert-Samier, A.; Ritchie, K.; Ohayon, M.M.; Besset, A.; Dauvilliers, Y. Excessive sleepiness is predictive of cognitive decline in the elderly. Sleep 2012, 35, 1201-1207. [CrossRef]

38. Andersen, P.K.; Gill, R.D. Cox's regression model for counting processes: A large sample study. Ann. Stat. 1982, 10, 1100-1120. [CrossRef]

39. Lysen, T.S.; Wolters, F.J.; Luik, A.I.; Ikram, M.K.; Tiemeier, H.; Ikram, M.A. Subjective Sleep Quality is not Associated with Incident Dementia: The Rotterdam Study. J. Alzheimers Dis. 2018, 64, 239-247. [CrossRef]

40. Green, M.J.; Espie, C.A.; Hunt, K.; Benzeval, M. The longitudinal course of insomnia symptoms: Inequalities by sex and occupational class among two different age cohorts followed for 20 years in the west of Scotland. Sleep 2012, 35, 815-823. [CrossRef]

41. Perlis, M.; Gehrman, P.; Ellis, J. The natural history of insomnia: What we know, don't know, and need to know. Sleep Med. Res. 2011, 2, 79-88. [CrossRef]

42. Yang, C.M.; Lin, S.C.; Cheng, C.P. Transient insomnia versus chronic insomnia: A comparison study of sleep-related psychological/behavioral characteristics. J. Clin. Psychol. 2013, 69, 1094-1107. [CrossRef]

43. Institute of Medicine (US) Committee on Sleep Medicine and Research. Extent and Health Consequences of Chronic Sleep Loss and Sleep Disorders: An Unmet Public Health Problem; Colten, H., Altenvogt, B., Eds.; National Academies Press: Washington, DC, USA, 2006.

44. Joo, E.Y. Structural brain neuroimaging in primary insomnia. Sleep Med. Res. 2015, 6, 50-53. [CrossRef]

45. Joo, E.Y.; Kim, H.; Suh, S.; Hong, S.B. Hippocampal substructural vulnerability to sleep disturbance and cognitive impairment in patients with chronic primary insomnia: Magnetic resonance imaging morphometry. Sleep 2014, 37, 1189-1198. [CrossRef]

46. Cross, N.E.; Lagopoulos, J.; Duffy, S.L.; Cockayne, N.L.; Hickie, I.B.; Lewis, S.J.; Naismith, S.L. Sleep quality in healthy older people: Relationship with (1)H magnetic resonance spectroscopy markers of glial and neuronal integrity. Behav. Neurosci. 2013, 127, 803-810. [CrossRef] [PubMed]

47. Rasmussen, M.K.; Mestre, H.; Nedergaard, M. The glymphatic pathway in neurological disorders. Lancet Neurol. 2018, 17, 1016-1024. [CrossRef] 
48. Xie, L.; Kang, H.; Xu, Q.; Chen, M.J.; Liao, Y.; Thiyagarajan, M.; O’Donnell, J.; Christensen, D.J.; Nicholson, C.; Iliff, J.J.; et al. Sleep drives metabolite clearance from the adult brain. Science 2013, 342, 373-377. [CrossRef] [PubMed]

49. Ju, Y.E.; Lucey, B.P.; Holtzman, D.M. Sleep and Alzheimer disease pathology-a bidirectional relationship. Nat. Rev. Neurol. 2014, 10, 115-119. [CrossRef] [PubMed]

50. Rozzini, L.; Conti, M.Z.; Riva, M.; Ceraso, A.; Caratozzolo, S.; Zanetti, M.; Padovani, A. Non-amnestic mild cognitive impairment and sleep complaints: A bidirectional relationship? Aging Clin. Exp. Res. 2018, 30, 661-668. [CrossRef]

51. Guarnieri, B.; Sorbi, S. Sleep and Cognitive Decline: A Strong Bidirectional Relationship. It Is Time for Specific Recommendations on Routine Assessment and the Management of Sleep Disorders in Patients with Mild Cognitive Impairment and Dementia. Eur. Neurol. 2015, 74, 43-48. [CrossRef] 